\section{The Dutch legal approach regarding health care decisions involving minors in the NGS days}

European Journal of Human Genetics (2017) 25, 166; doi:10.1038/ejhg.2016.159; published online 23 November 2016

We thank Sénécal and colleagues for addressing the important issue of the legal position of minors, involved in healthcare decisions, with particular attention to the context of next-generation sequencing. ${ }^{1}$ The authors conclude that the legal frameworks of the 28 Member States of the European Union and Canada differ on the minor's right to provide consent for medical treatment. As to the latter, they identify three different approaches: 1) Legally-fixed age for capacity to consent to medical interventions; 2) competence-based approach; 3) mixed approaches. The Dutch legal framework fits within the first approach. In this respect, the authors further distinguish between frameworks using merely a fixed age threshold, from which minors should provide consent for medical treatment, and frameworks which include additional conditions and/or exceptions. According to the authors, the Netherlands fit within this first category. We would like to stress that this is not an accurate representation of Dutch law. On the basis of the Dutch Medical Treatment Contract Act of 1995, minors aged 16 and older are in principle capable to decide on their own about medical treatment. However, children aged 12-16 have the right to consent to medical treatment (unless they are not yet capable to do so, for instance, due to a cognitive impairment), but they cannot exercise this right independently: their parents need to consent too. ${ }^{2}$ This 'dual consent system' is not absolute, that is, situations could occur, in which a refusal by (one of) the parents can be ignored, for instance, if a refusal would have serious negative consequences for the health (prospects) of the child. We think it is important to add these principles to the article of Sénécal et al ${ }^{1}$ because they constitute a core element of the Dutch legal framework regarding the legal position of minors, both in care and research.

\section{CONFLICT OF INTEREST}

The authors declare no conflict of interest.

Elcke J Kranendonk ${ }^{*}, 1$ Raoul C Hennekam ${ }^{2}$ and
Martine Corrette Ploem ${ }^{1}$
${ }^{1}$ Department of Public Health, AMC, University of Amsterdam,
Amsterdam, The Netherlands;
${ }^{2}$ Departments of Paediatrics and Translational Genetics, AMC, University
of Amsterdam, Amsterdam, The Netherlands
E-mail: e.j.kranendonk@amc.uva.nl

1 Sénécal K, Thys K, Vears DF, Van Assche K, Knoppers BM, Borry P: Legal approaches regarding health-care decisions involving minors: implications for next-generation sequencing, Eur J Hum Genet 2016; 24: 1559-1564.

2 Kranendonk EJ, Ploem MC, Hennekam RC: Regulating biobanking with children's tissue: a legal analysis and the experts' view. Eur J Hum Genet 2016; 24: 30-36.

\section{Reply to Kranendonk et al}

European Journal of Human Genetics (2017) 25, 166-167; doi:10.1038/ejhg.2016.160; published online 23 November 2016

We appreciate the comments provided by Kranendonk et al. ${ }^{1}$ on our published article describing the existing legal approaches regarding the rights of minors to consent to health-care interventions, ${ }^{2}$ including how laws in the 28 member states of the European Union and in Canada consider competent minors. We are in agreement with the nuances provided by Kranendonk et al. concerning minors aged 12-16 years in the Netherlands. As a matter of fact, this nuance was clearly included in the Supplementary Information that accompanies our manuscript, and available online since the publication of the manuscript. (http://www.nature.com/ejhg/journal/vaop/ncurrent/suppinfo/ ejhg201661s1.html). These nuances are also found in a 2015 article to be published in the November/December 2016 issue of IRB: Ethics \& Human Research. ${ }^{3}$

In our EJHG article, the objective was to present the general approaches that state the question of whether, and from what age, minors can generally provide lawful consent to health-care interventions. We have taken the Dutch law as an example to demonstrate that the fixed age of capacity to consent to medical care is sometimes set at a different age than the age of legal majority. In no case did we intend to over-simplify the Dutch law. However, presenting an in-depth analysis of all legal complexities surrounding the concept of mature minors in each of the countries under study was not possible. Well aware of the importance of these nuances and exceptions, we did include them in our publication by attaching them to our analysis tables that contain such legal nuances and exceptions. We invite the readers to refer to the Supplementary Information and to note that our article aims to present the general legal approach, but not an exhaustive legal analysis for each country included in this research.

The other point raised by Kranendonk et al. concerning parental refusal which would have serious negative consequences for the child, describes a situation foreseen in most child protection legislation around the world and would constitute reportable 'medical neglect'. The EJHG article neither included a systematic review of this subject nor of such legislation.

\section{CONFLICT OF INTEREST}

The authors declare no conflict of interest. 


\author{
K Sénécal ${ }^{\star, 1}, \mathrm{~K}$ Thys ${ }^{2}$, DF Vears ${ }^{2}, \mathrm{~K}$ Van Assche $^{3}$, \\ BM Knoppers ${ }^{1}$ and P Borry ${ }^{2}$ \\ ${ }^{1}$ Centre of Genomics and Policy, Department of Human Genetics, McGill \\ University, Montreal, Quebec, Canada; \\ ${ }^{2}$ Centre for Biomedical Ethics and Law, Department of Public Health and \\ Primary Care, KU Leuven, Leuven, Belgium; \\ ${ }^{3}$ Research Group on Personality Rights and Property Rights, Faculty of \\ Law, University of Antwerp, Antwerp, Belgium \\ E-mail: karine.senecal@mcgill.ca
}

1 Kranendonk EJ, Hennekam RC, Ploem MC. The Dutch Legal Approach Regarding Health Care Decisions Involving Minors in the NGS days. Eur J Hum Genet 2016.

2 Sénécal K, Thys K, Vears DF, Van Assche K, Knoppers BM, Borry P: Legal approaches regarding health-care decisions involving minors: implications for next-generation sequencing. Eur J Hum Genet 2016; 24: 1559-1564.

3 Knoppers BM, Sénécal K, Boisjoli J et al: on behalf of the P3G International Paediatric Research Program: Recontacting pediatric research participants for consent when they reach the age of majority. IRB Ethics Hum Res 2016; 1-9.

\section{BRCA1/2 germline testing in non-mucinous epithelial ovarian carcinoma: changing international practice and implications for service provision}

European Journal of Human Genetics (2017) 25, 167-168; doi:10.1038/ejhg.2016.138; published online 19 October 2016

Ovarian carcinoma is the fourth most common cancer for women in Republic of Ireland, with an average of 361 cases per year. ${ }^{1}$ The association with germline mutations in $B R C A 1 / 2$ genes in non-mucinous ovarian cancer risk is well established. ${ }^{2}$ Determining the BRCA status of ovarian cancer patients has important prognostic and therapeutic implications for individual patients. ${ }^{3}$ The frequency of BRCA1/2 germline mutations in non-mucinous ovarian carcinoma is estimated at $14-15 \%,{ }^{2}$ with previous studies finding a higher rate of $16.6 \%$ in serous ovarian carcinoma and $17.1 \%$ in high-grade serous carcinoma. ${ }^{3}$ Family history has been shown not to be sufficiently accurate to predict mutation status. ${ }^{2,3}$ In Ireland, as in most European countries, and the United States, the current recommendation is that patients with a family history of breast/ ovarian cancer should be offered full mutation screening of the $B R C A 1 / 2$ genes as appropriate following the assessment by a clinical genetics service. ${ }^{4}$

The landscape of germline mutation status testing is rapidly evolving. BRCA1/2 genes were merely discovered in the early $1990 \mathrm{~s}$, however in 2016, the genes are known to have important prognostic and therapeutic implications, most notably with Inhibitors of poly (ADP-ribose) polymerase (PARP inhibitors), such as olaparib showing antitumour activity in cancer associated with the BRCA1/2 mutation. ${ }^{5}$ The NCCN guidelines have been updated to recommend PARP inhibitors in patients with germline BRCA $1 / 2$ mutations. ${ }^{6}$ In some health-care systems, for example, in Austria ${ }^{7}$ and in Ontario, Canada, ${ }^{8}$ BRCA1/2 germline mutation testing is offered for all non-mucinous or serous epithelial carcinoma.

Hoberg-Vetti et al. ${ }^{9}$ in EJHG September 2015, detailed the high acceptability of germline mutation status testing to patients, and further recommended germline BRCA1/2 testing in all patients with epithelial ovarian cancer owing to the high prevalence of pathogenic BRCA1/2 variants in this group.

As a result, we anticipate germline mutation status testing in serous epithelial ovarian carcinoma will soon be recommended as routine internationally, and attempted to quantify the impact such a recommendation may bear on Irish oncology and genetic services.

\section{A SINGLE CENTRE EXPERIENCE OF BRCA1/2 GERMLINE MUTATION TESTING IN OVARIAN CARCINOMA}

In a large Irish tertiary referral centre, Cork University Hospital, over a 12-month period, January-December 2014, we identified patients with ovarian cancer, excluding cases of borderline, germ cell and sarcomatoid tumours. A total of 71 patients were identified, all females with a mean age of 58 years (range; 22-85 years). Seventy-six per cent of patients (54/71) had non-mucinous epithelial ovarian carcinoma and $24 \%$ (17/71) of patients had non-epithelial/mucinous ovarian carcinomas. Fourteen per cent (10/71) were investigated for germline BRCA1/2 mutations and $50 \%$ of these cases are confirmed positive for germline BRCA1/2 mutations.

Therefore, with the current recommendation of family history as the gateway to entry to the genetic testing pathway, we have a high positive test rate $(50 \%)$; that is, family history tends to correctly identify those most likely to carry BRCA1/2 germline mutations. However, were all non-mucinous epithelial tumours eligible for testing, 45 more patients in our centre would have been tested, and with a $14 \%$ positive test rate, this may have identified a further six to seven patients with germline mutations of the BRCA1/2 genes.

\section{NATIONAL AND INTERNATIONAL IMPLICATIONS}

If these data were extrapolated to apply to all cases in Ireland, of 361 cases (the yearly average), this may result in a further 274 cases eligible for testing per year, with $\sim 38$ more patients identified with BRCA1/2 mutations per year in Ireland.

In Ireland, as would be the case in many European countries, this has great implications for genetic service provision. Not only will increased resources for laboratory testing be required, but greater resources will be required to ensure training of expertise in genetics and genetic counselling, especially with regard to interpretation of variance of uncertain significance.

Alternative models for genetic counselling are rapidly being developed, such as telephone counselling, ${ }^{10}$ and we recommend that patients with ovarian carcinoma are included in newer pathways to allow for easier access to genetic information and psychological support.

In summary, we anticipate a surge in demand for genetics services, including genetic counselling, in the coming years and advise that healthcare systems address this anticipated demand in resource planning. 